\title{
Psychological Difficulties and Level of Knowledge of Medical Staff Identifying Donors after Irreversible Cardiac Arrest
}

Edyta Skwirczyńska $^{1 *}$, Natalia Serwin ${ }^{2}$, Oskar Wróblewski ${ }^{1}$, Maria Ustianowska ${ }^{1}$, Maciej Kotowski ${ }^{3}$, Karol Tejchman $^{3}$ and Marek Ostrowski $^{3}$

${ }^{1}$ Department of History of Medicine and Ethics, Pomeranian Medical University of Szczecin, Poland

${ }^{2}$ Department of Microbiology and Immunology, Pomeranian Medical University of Szczecin, Poland

${ }^{3}$ Department of General Surgery and Transplantation, Pomeranian Medical University of Szczecin, Poland

\begin{abstract}
Over the last fifty years, organ transplantation has become a routine medical procedure, bringing immense benefits to the patients. In Poland, to 2018 by DBD donors (Donor after Brain Death) accounted for about $95 \%$ of all donors and about $5 \%$ were living donors. A completely unused group are DCD donors (Donors after Cardiac Death).

Material and Methods: The survey was done among 500 people from medical staff of intensive care unit and intensive cardiological care where the probability of receiving anonymous donation after circulatory death is the highest, yet only 368 people had filled the survey and their cases were taken into consideration as far as the study was concerned. The rest of people surveyed were not taken into consideration as they had not filled the survey. The survey was conducted in the form of a self-projected questionnaire based on Hospital Attitude Survey.

Results: The study showed that $98.4 \%$ of respondents accept the transplant. As many as $93.1 \%$ of people did not know the Maastricht classification and $57.5 \%$ claimed that in Poland there is a permission to take organs from people with a non-beating heart.

Discussion: The study found that perceiving the potential of heart-warming donations from donors depends on their professional position. Unlike nurses, the doctor does not see the potential of transplantation from donors with a non-beating heart. Referring to the results of studies in other countries of the European Union, there is an immense difference between personal attitude towards organ donation from patients after brain death DBD and towards patients after circulatory death DCD.
\end{abstract}

Keywords: Organ transplantation; Patients; Intensive care unit

\section{Introduction}

Over the last 50 years, the average waiting time for organ transplantation in Poland was 10 months. Some people placed on the organ transplant list have never received one. An important issue is to find solutions to increase the number of donors. DBD donors (donors after irreversible cessation of brain function) accounted for about $95 \%$ of all, whereas less than $5 \%$ of donors were alive statistically in Poland since 2015.

A completely unused group of potential organ donors is a group of DCD donors (donors after irreversible detention of circulation). The subject of this work is the assessment of the level of knowledge of medical staff working in the intensive care ward and intensive cardiac care ward. In those wards there is the highest probability of potential identification of the donor who died as a result of the mechanism of irreversible detention of circulation (DCD donor). The type and nature of necessary training were determined in the conducted study, as well as a form which the staff would be most eager to take part in. No potential donor has been reported and no organ has been taken from the DCD donor in Poland until 2014. Poltransplant statistics show that only in 2015 there were reported 3 potential DCD donors $(0.4 \%$, DBD donors: $703-99.6 \%)$. In 2016, 9 potential candidates were reported as DCD donors (1.3\%) [1] despite the existence of a law permitting organ donation from DCD donors of type I, II, IV.

Over the last fifty years, organ transplantation has become a routine medical procedure that has greatly benefited many patients [2]. Recent 20 years have presented steady growth in the number of human organs used for transplantation. It is currently the most costeffective treatment for end-stage renal failure and the only available treatment for end-stage disease of organs such as the liver, lung and heart. Insufficient number of organs for transplantation is the basic limitation and problem faced by transplantologists around the world.
Knowledge and a positive attitude towards transplantation among healthcare professionals are necessary to increase the percentage of organ donation and transplantation. Poland was one of the 18 countries which participated in the long-term (2007-2009) ETPOD (European Training Program on Organ Donation) project. The basis of the project was to increase general knowledge about donors after brain death (DBD) and awareness of organ donation [3,4]. The use of organs from DCD donors is now another possible way to extend the limited donor pool [5]. Four categories of DCD donors were identified and described as part of the first international DCD conference in Maastricht In 1995.

Type I: patients who died before arrival at the hospital to whom any resuscitation is not advisable. Type II: patients who died of irreversible cardiac arrest caused most often by heart diseases, bleeding into the central nervous system. Type III: patients with severe damage to the central nervous system that does not meet the criterion of brain death. Type IV: donors who were diagnosed with brain death based on valid criteria. First category represents uncontrolled donors and includes DCD donors type I and II. Second category consists of controlled donors who can be divided into two types, III and IV. Polish law does not allow donation of organs which belong to type III donors. The aim of this study was to assess the knowledge and to analyze training

*Corresponding author: Edyta Skwirczyńska, Department of History of Medicine and Ethics, Pomeranian Medical University of Szczecin, Poland, Tel: +48 508359596; E-mail: edytas@pum.edu.pl

Received: October 16, 2018; Accepted: November 05, 2018; Published: November 12, 2018

Citation: Skwirczyńska E, Serwin N, Wróblewski O, Ustianowska M, Kotowski M et al. (2018) Psychological Difficulties and Level of Knowledge of Medical Staff Identifying Donors after Irreversible Cardiac Arrest. Prim Health Care 8: 314. doi: 10.4172/2167-1079.1000314

Copyright: () 2018 Skwirczyńska E, et al. This is an open-access article distributed under the terms of the Creative Commons Attribution License, which permits unrestricted use, distribution, and reproduction in any medium, provided the original author and source are credited. 
needs of medical staff of intensive care units and intensive cardiac care departments in the field of donation of organs from donors who died as a result of irreversible cardiac arrest (DCD).

\section{Material and Methods}

The study used a questionnaire based on HAS one (Hospital Attitude Survey). It was designated for doctors and nurses from those units in which identification of DCD donors is mostly plausible. The questionnaire consisted of 23 questions, 20 of them were closed ones and 3 of them were open ones in which the respondent was free to express his opinion. The questions tested the knowledge of procedures regarding the organ procurement and care of DCD donors. The questionnaire also checked whether the personnel were competent enough to identify DCD donors and whether the personnel were familiar with provisions of the Maastricht classification of DCD donors. The research covered 500 employees of hospitals in the West Pomeranian, Pomeranian and Lubuskie voivodships, 368 of all returned the questionnaire. The study did not reject incomplete questionnaires, information on the number of respondents who marked the same answers in individual questions was included in the statistical description. The study covered medical personnel from Intensive Care Units (ICU) and intensive cardiac care. The selection of units was determined by the highest probability of contact with potential donors after irreversible cardiac arrest (DCD). The sample included women $\mathrm{N}=282, \mathrm{M}=42.50, \mathrm{SD}=8.23$ and men $\mathrm{N}=86, \mathrm{M}=40.59$, $\mathrm{SD}=9.50$ working as doctors and nurses serving the above-mentioned hospital wards. The questions in the questionnaire dealt with issues related to transplants as a treatment option [6-8].

\section{Results}

Statistical analyzes were performed using the IBM SPSS Statistics 23 package, which was used to analyze basic descriptive statistics and to check the chi square independence test. The level of significance was considered $\mathrm{p}<0.05$ and the results as $0.05<\mathrm{p}<0.1$ were statistically significant. Statistical analysis was carried out using the chi square independence test. It was checked whether there are statistically significant relationships between the professional position of the examined persons and their knowledge of the criteria necessary for the identification of a potential DCD donor. The conducted analysis turned out to be statistically significant. There is a weak correlation between professional position and death criterion, Cramer's V=0.21. The professional position certainly has an impact on the death criteria. In the next study, it was checked whether there were significant statistical relationships between the professional position of the respondents and their knowledge of transplantation from donors who died as a result of irreversible cardiac arrest. The conducted analysis also turned out to be statistically significant. Variables such as occupational status and the percentage of donors in other countries are not independent. There is a strong correlation between Cramer's V variables $=0.82$. The study showed that the perception of the organ donation potential depends on the professional position of the medical staff. Unlike nurses, doctors do not see the potential of transplantation from donors after irreversible cardiac arrest. Only 6 out of 118 doctors who responded to the questionnaire indicated that in their opinion the percentage of donors after irreversible cardiac arrest in other countries ranges from $25 \%$ to $50 \%$. Among the nurses' group, as many as 104 indicated that the percentage of DCD donors in other countries ranged from $25 \%$ to $50 \%$. The study showed that $98.4 \%$ of respondents accept a transplant as a treatment method. Analysis of attitudes revealed that $79.1 \%$ of respondents declared acceptance of neurological criteria as adequate to diagnose death in the case of a potential organ donor, $12 \%$ of respondents indicated circulation criteria, only $8.9 \%$ declared both criteria as suitable for the diagnosis of death. A significant percentage of respondents (79.3\%) do not accept equivalent consideration of cardiovascular and neurological criteria as suitable for diagnosing the death of a potential donor. Despite the declarations of knowledge of DCD and NHBD (Non-Heart-Beating Donor) terms, the vast majority of respondents (93.1\%) did not know the Maastricht classification and $84.5 \%$ did not know the procedures related to the identification of DCD donors. The main organs mentioned by the respondents as those that could qualify for DCD donation were kidneys (32\%), liver (19\%) and cornea (22\%). More than half of the respondents did not know if there was a difference in the risk of acute rejection of the kidney taken from the DCD donor and that harvested from the DBD donor. A larger percentage of respondents indicated that there were no cases of identifying the donor after irreversible cardiac arrest in their unit in the last calendar year. $90 \%$ of respondents expressed their willingness to participate in training and $70 \%$ of them were interested in the subject of the training presented in the questionnaire. $40 \%$ of respondents declared willingness to participate in the training in identification of donors with a "beatless" heart. The training in interviewing the potential donor family was less popular $(<30 \%)$. Studies have shown that the optimal training time is $2-3$ hours as training sessions carried out at the workplace in the morning. A helpful solution proposed by respondents regarding the notification of potential organ donors was social education and training of medical personnel (Figure 1).

\section{Discussion}

The main factors associated with the organ procurement and identification of donors are goodwill, knowledge and qualifications of employees of ICU and Intensive Cardiac Care Departments. The attitude of medical personnel to the idea of transplantation is extremely important. As far as the psychological approach is concerned, difficult moment for medical staff is the situation in which the effort made to save the patient's life goes to waste at the time of his death. Referring to the results of research carried out in other European Union countries and other countries around the world, there are noticeable difficulties and significant differences in personal attitudes towards the identification of organs in mentioned two types of donors, those after the irreversible cessation of brain function and donors after irreversible cardiac arrest. The cohort population was based on the potential donors of a

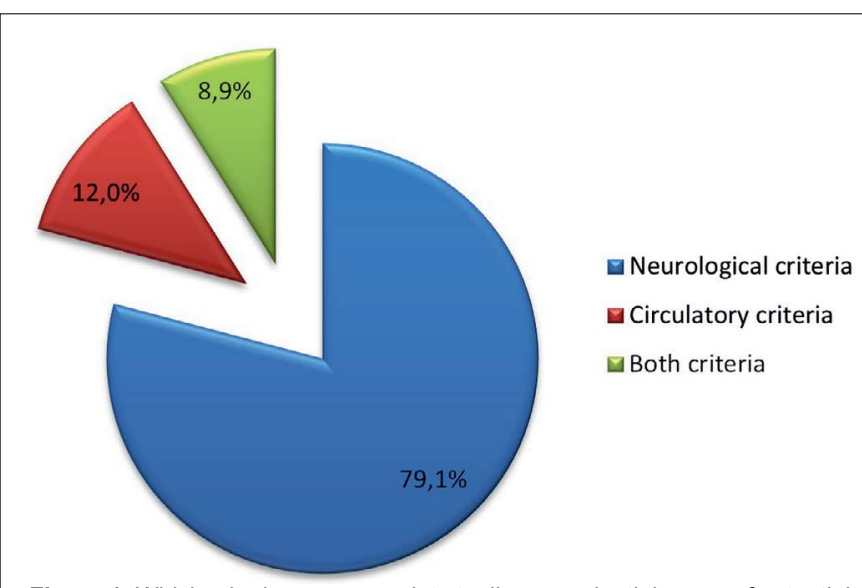

Figure 1: Which criteria are appropriate to diagnose death in case of potential organ donor? 
controlled type of DCD in the Donor of the Donation Program of Life (DSA), which includes eastern Pennsylvania, southern New Jersey and Delaware. Based on a census from 2000, this area included 10.2 million Americans or $3.62 \%$ of the US population [9]. The annual survey of 130 out of 21802 deaths in the 50 hospitals studied were potentially eligible DCDs. Out of these potential DCDs, clinicians identified 108 patients (49 optimal and 59 non-optimal, 83.1\%) before OPO before discontinuing life support therapy. Among 108 potential DCDs that were identified and sent back, 108 organs were actually transplanted from 50 donors (2.16 organ per donor). The lack of transplantation from the other 58 identified potential donors was due to family refusals or because the organs were considered unsuitable for transplantation at the time of recovery [10]. In Belgium, Vincent and his colleagues from University Libre de Bruxeles carried out a study using a short questionnaire which defined the attitudes and feelings of nursing staff in the intensive care unit with reference to established donors after the program of cardiac death. Despite several educational sessions, only $3 \%$ of nurses felt that they were adequately informed about DCD. $38 \%$ of nurses were less comfortable with DCD than with donation of DBD organs. $76 \%$ of nurses needed additional information about DCD procedures [11,12]. With regard to the pilot study of Zellweger and colleagues on the experiences of the nurses and medical staff at university hospitals in Geneva, Polish medical staff answering to open questions also focused on psychological aspects. Difficulties were related to family contact and criteria for the identification of a DCD donor (Figures 2 and 3).

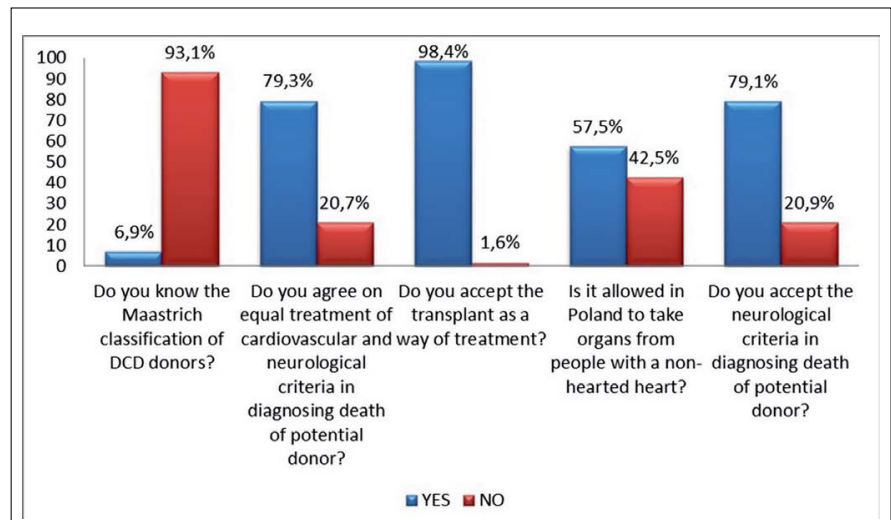

Figure 2: Research about knowledge medical personnel on DCD donors.

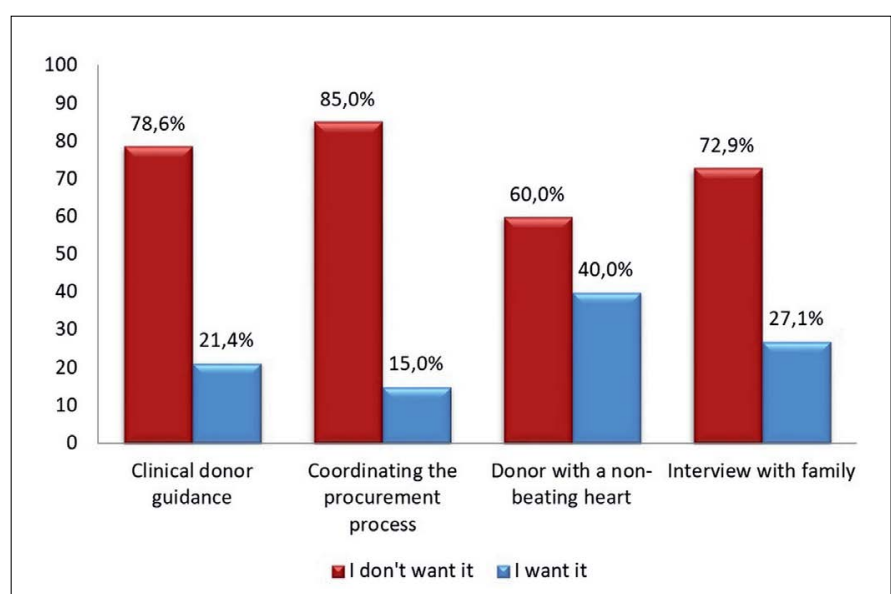

Figure 3: Percentage of responses willing to participate in trainings.

\section{Conclusion}

The success of the transplantation is based on the cooperation and professional knowledge of medical personnel involved in the process of identification and allocation of DCD. Regular training and psychological support is required for medical personnel so that they can feel suitably qualified. It will significantly increase comfort and affect the confidence in making decisions. Emphasis should be placed, above all, on the transparency of procedures to avoid possible doubts [13]. A detailed analysis of the requirements in terms of staff knowledge and training has created the need to prepare training sessions to disseminate knowledge about DCD donors and organ transplantation from those donors. It is also necessary to familiarize with the procedures regarding the identification of them. The study also indicates the need for psychological support for medical personnel involved in the process of identification of DCD donors.

\section{Acknowledgement}

This research did not receive any specific grant from funding agencies in the public, commercial, or not-for-profit sectors. Contributions made to this study by the authors are as following: ES and MO, participated in the design and concept of the study. ES, NS participated in the collection and analysis of data. ES and OW are the authors of the first draft of manuscript. ES, OW, MU, are participated in the writing of the manuscript. All authors reviewed the manuscript.

\section{References}

1. Antoszkiewicz K, Czerwinski J (2017) Collection and transplantation of organs in Poland in 2016. Poltransplant Bulletin 25: 19-34.

2. Ostrowski M, Skwirczynska E, Serwin N, Zair L, Serwin K, et al. (2018) Renal transplantation after removal of chromophobe renal cell carcinoma in donor kidney: A case report. Medical Sci Case Reports 5:41-45.

3. Union I (2014) Communication from the commission to the European parliament, the council, the European economic and social committee and the committee of the Regions. Brussels.

4. Woderska A, Czerwinski J, Michalak G (2009) ETPOD-European training program on organ donation. The european commission project. Ann Transplant 14: 79-79.

5. Manyalich M, Guasch X, Paez G, Valero R, Istrate M (2013) ETPOD (European training program on organ donation): A successful training program to improve organ donation. Transpl Int 26: 373-384.

6. Gulsen MT, Girotra M, Cengiz-Seval G, Price J, Singh VK, et al. (2013) HTK preservative solution is associated with increased biliary complications among patients receiving DCD liver transplants: A single center experience. Ann Transplant 18: 69-75.

7. Fondevila C, Hessheimer AJ, Flores E, Ruiz A, Mestres N, et al. (2012) Applicability and results of Maastricht type 2 donation after cardiac death live transplantation. Am J Transplant 12: 162-170.

8. The Act of July 17,2009 . on the amendment of the act on the collection, storage and transplantation of cells, tissues and organs and on the amendment of the Act (2009).

9. Announcement of the Minister of Health of 9 August 2010 on the criteria and manner of finding irreversible cardiac arrest (2010) Monitor Polski.

10. Halpern SD, Truog RD (2010) Organ donors after circulatory determination of death: Not necessarily dead and it does not necessarily matter. Crit Care Med 38: 1011-1012.

11. Halpern SD, Hasz RD, Abt PL (2013) Incidence and distribution of transplantable organs from donors after circulatory determination of death in US intensive care units. Ann Am Thorac Soc 10: 73-80.

12. Vincent JL, Maetens $Y$, Vanderwallen $C$, Van Nuffelen M, Wissing M, et al (2009) Non-heart-beating donors: An inquiry to ICU nurses in a Belgian university hospital. Transplant Proc 41: 579-581.

13. Zellweger A, Gasche Y, Moretti D, Majmou H, Cedraschi C (2017) A qualitative pilot study on donation after cardiac death (DCD): Feelings experienced by the nursing and medical staff in the adult intensive care unit (ICU) of the Geneva university hospitals. Transplantation 101: S22. 